\title{
L'association de HLA-DR avec un peptide unique vue en trois dimensions
}

Les protéines du complexe majeur d'histocompatibilité (CMH) transportent jusqu'à la surface cellulaire, et présentent aux lymphocytes $\mathrm{T}$, des peptides provenant de la dégradation des protéines synthétisées ou internalisées par une cellule. Le CMH-I stimule les lymphocytes $\mathrm{T}$ CD8 cytotoxiques reconnaissant essentiellement des peptides de protéines virales. Les lymphocytes $\mathrm{T}$ CD4 auxiliaires sont activés par la reconnaissance de peptides présentés par le CMH-II qui dérivent principalement des protéines internalisées dans la voie d'endocytose. Les CMH-I et II ont une structure similaire malgré une organisation en domaine différente $[1,2]$. Le site de fixation des peptides est formé par huit feuillets $\alpha$ bordés par deux hélices $\alpha$ et les résidus polymorphiques du $\mathrm{CMH}$ sont concentrés à ce niveau, expliquant des spécificités peptidiques variables selon les allèles. Le CMH-I fixe des peptides de huit à dix acides aminés et des motifs peptidiques spécifiques d'allèles sont caractérisés par la présence préférentielle de quelques chaines latérales d'acides aminés à des positions définies du ligand [3]. Quelle que soit leur séquence, les peptides se fixent au CMH-I de manière identique: des liaisons hydrogène avec des acides aminés conservés dans tous les allèles $\mathrm{CMH}-1$ séquestrent les extrémités des peptides dans le sillon accepteur. Selon leur longueur, les peptides sont étirés dans le sillon ou bombés en leur milieu [4]. Pour le CMH-II les peptides ne semblent pas avoir de stricte limitation de taille, ce qui rend difficile l'identification des motifs peptidiques spécifiques d'allèles $[5,6]$. La structure cristalline du CMH-II (HLA-DRI), résolue à 3,3 $\AA$, a montré que les extrémités des peptides débordent du sillon [2], mais il a fallu attendre les cristaux de $\mathrm{CMH}$-II associé à un peptide par- influenza (peptide HA de 13 acides aminés) pour interpréter en détail les interactions entre le peptide et son site accepteur. La structure fine $(2,75$ Å) du complexe HLA$\mathrm{DR} 1 /$ peptide HA révèle que le peptide se trouve sous forme d'une chaîne étirée et torsadée dont les extrémités sont projetées hors du site accepteur [7]. Cette conformation autorise les interactions entre le sillon et les chaînes latérales de certains acides aminés, tout en permettant la reconnaissance directe du peptide par le récepteur de l'antigène des lymphocytes $T$ auxiliaires. En effet, environ $35 \%$ de la surface du peptide (soit $750 \AA$ A) restent accessibles au solvant et représentent une zone d'interaction potentielle avec le récepteur de l'antigène. Les deux extrémités du peptide ne semblent intervenir, ni dans la liaison avec le $\mathrm{CMH}$, ni dans la reconnaissance par les lymphocytes T. Parmi les quinze liaisons hydrogène observées entre HIA-DRl et les atomes de la chaîne principale du peptide, douze impliquent des acides aminés monomorphiques conservés chez l'homme et la souris. Les ponts hydrogène sont répartis uniformément le long de l'ossature peptidique. Puisqu'elles ne font intervenir, ni les chaînes latérales d'acides aminés, ni les résidus polymorphiques du CMH-II, ces liaisons hydrogène pourraient être un mode de fixation universel du ligand à son récepteur, indépendant des variations de séquence de l'un ou de l'autre. En revanche, les cinq petites cavités du sillon dans lesquelles s'engagent les chaînes latérales d'acides aminés du peptide sont bordées de résidus polymorphiques. Elles détermineraient la spécificité de fixation de certains peptides sur les différents allèles du CMH-Il. L'importance d'autres chaînes latérales du peptide HA qui entrent en contact avec HIA-DRl est plus difficile à apprécier. Parce que la plupart des cavi- tés peuvent être remplies par des chaînes latérales différentes mais de structure similaire, et parce que la formation des liaisons hydrogène avec l'ossature peptidique est indépendante de la séquence du ligand, la molécule HIA-DRl peut fixer une grande variété de peptides avec une forte affinité, de l'ordre du nanomolaire. Si la conformation des peptides liés au CMH-II était toujours proche de celle observée pour le peptide HA associé à HIA-DRl, il deviendrait possible de définir, par les chaînes latérales d'acides aminés du ligand, des motifs d'association spécifiques d'allèles. Un progrès énorme si l'on présume qu'un jour, une réponse immunitaire pourra être manipulée à l'aide de peptides agonistes et antagonistes.

V.L.

1. Bojrkman PJ, Saper MA, Samraoui B, et al. Structure of the human class 1 histocompatibility antigen HLA-A2. Nalure 1987; 329: 506-12.

2. Brown JH, Jardetsky TS, Gorga JC, et al. Three dimensional structure of the human class II histocompatibility antigen HLA-DR1. Nature 1993; 364: 33-9.

3. Falk K, Rotzschke (), Stevanovic S, Jung G, Rammensee HG. Allele specific motif's revealed by sequencing of self peptides eluted from MHC molecules. Nature 1991; 351: 290-6.

4. Kiahn A. La troisième dimension pour les molécules de classe 1 du complexe majeur d'histocompatibilité: un cristal de HLA-A2. médecine/sciences $1988 ; 4$ : 52-4.

5. Rudensky AY, Preston-Hurlburt P, AlRamadi BK, Rothbard J, Janeway CA. Truncation variants of peptides isolated from MHC; class II molecules suggest sequence motifs. Nature 1992; 359: 429-31.

6. Chicz RM, Urban RG, I ane W'S, Gorga JC, Stern L.J, Vignali DAA, Strominger JL. Predominant naturally processed peptides bound to HIA-DRI are derived from MHC; related molecules and are heterogeneous in size. Nalure 1992; 358: 764-8.

7. Stern IJJ, Brown JH, Jardetsky TS, Gorga JC, Yrban RG, Surominger JL, Wiley DC. Crystal structure of the human class II MHC protein HLA-DRI complexed with an influenza virus peptide. Nature 1994; 368: 215-21. 